\title{
Overview of Comprehensive Hepatitis C Virus Medication Management in a State Medicaid Program
}

\author{
Pavel Lavitas, PharmD, BCPS; Mark Tesell, PharmD, BCPS; Tasmina Hydery, PharmD, MBA, CGP; \\ Bonnie C. Greenwood, PharmD, BCPS; Mylissa Price, RPh, MPH; Kimberly Lenz, PharmD; \\ and Paul Jeffrey, PharmD
}

\begin{abstract}
BACKGROUND: Breakthrough direct-acting antivirals set a new standard in the management of hepatitis $\mathrm{C}$ virus (HCV) with regard to cure rates and improved tolerability; however, the health care system is challenged by the cost of these medications.
\end{abstract}

OBJECTIVE: To describe the effect of a comprehensive HCV medication management program on optimized regimen use, prior authorization (PA) modifications, and medication cost avoidance in a state Medicaid program.

METHODS: This program consists of a 2-tiered prescriber outreach: (1) regimen outreach to promote optimized regimen selection and (2) refill outreach to support medication adherence. PA criteria were developed to identify optimized regimens, taking into account member- and virus-specific factors as well as cost. Prescriber outreach was conducted to recommend the use of an optimized regimen as applicable. Successful regimen outreach was defined as the number of members for whom a recommendation was accepted. A refill report identified members without a subsequent paid HCV medication claim within 25 days of the previous claim and outreach to the prescriber's office was performed. The outcome measure for refill outreach was the number and type of PA modifications made secondary to outreach (closure or extension). Cost avoidance was calculated for members who completed treatment with an optimized regimen. Return on investment (ROI) was calculated for the program.

RESULTS: Between December 18, 2013, and January 31, 2015, 911 members had PA requests approved for simeprevir, sofosbuvir, or ledipasvir/ sofosbuvir. Of these members, $223(24.5 \%)$ met the criteria for regimen outreach. Pharmacist interventions to treat with an optimized regimen were accepted for 135 members (60.5\%). Following implementation of prescriber outreach to promote refills, between March 10, 2014, and January 31, 2015, offices were informed of an upcoming refill for 515 members. As a result of outreach, $19.6 \%$ of members had a subsequent PA modification. Sixty-nine approved PAs (for 68 members) were closed after correspondence with the prescriber, and 33 approved PAs (for 33 members) were extended. The total projected cost avoidance was $\$ 3,770,097$. The comprehensive HCV medication management program demonstrated an ROI of $\$ 10.28$ for every $\$ 1$ spent.

CONCLUSIONS: A comprehensive HCV medication management program can help contain costs while ensuring that members have access to most clinically appropriate regimens.

J Manag Care Spec Pharm. 2016;22(10):1161-66

Copyright @ 2016, Academy of Managed Care Pharmacy. All rights reserved.

\section{What is already known about this subject}

Since 2013, there have been several pharmaceutical breakthroughs for the treatment of hepatitis $\mathrm{C}$ virus (HCV) infection, offering higher cure rates, improved dosing strategies, and fewer side effects.

The high cost of HCV treatments has prompted payers to develop comprehensive management programs that ensure optimal use of therapy.

\section{What this study adds}

This study describes the impact of comprehensive HCV medication management in a state Medicaid program that includes detailed clinical criteria and prescriber outreach to recommend optimized regimens and provide refill reminders.

Utilizing dynamic clinical criteria that incorporate the most recent evidence-based medicine and consensus guidelines, prescriber outreach was performed to recommend an optimized regimen for $24.5 \%$ of members with a prior authorization approval for a novel HCV regimen; prescribers accepted $60.5 \%$ of these recommendations.

Optimized regimens resulted in an estimated cost avoidance of over $\$ 3.7$ million in members completing treatment, and the medication management program averted $\$ 10.28$ in medication spend for every $\$ 1$ spent.

T $\mathrm{t}$ is estimated that between 2.7 and 3.9 million people in the United States have chronic hepatitis C virus (HCV) 1 infection, and as of 2013, less than 10\% of these patients achieved cure..$^{-4}$ Over half of those infected with HCV are undiagnosed, and for those who are diagnosed, limited access to health care and disease staging, lack of ability and/or willingness to start treatment, poor adherence, and lack of followup testing are barriers to achieving cure., 3,4

In 2013, 2 direct-acting antivirals, sofosbuvir (Sovaldi) and simeprevir (Olysio), were approved by the U.S. Food and Drug Administration (FDA) as part of combination treatment for HCV. These regimens have set a standard for higher cure rates and improved tolerability over previous regimens. The American Association for the Study of Liver Diseases and Infectious Diseases Society of America (AASLD/IDSA) provide 
joint recommendations for the testing, management, and treatment of HCV that are regularly updated to reflect ongoing approval of breakthrough HCV medications. ${ }^{5}$

The health care system, however, is challenged by the high cost of these medications. A recent analysis estimated that it will cost payers $\$ 136$ billion for HCV treatment over the next 5 years, of which $\$ 61$ billion will be paid by the government. ${ }^{6}$ Beyond cost considerations, nonadherence is a known issue for patients treated with HCV regimens because of regimen complexity, pill burden, toxicity, and drug interactions. ${ }^{7,8}$ All oral regimens promise improvements because of more favorable side effect profiles and greater patient acceptance of oral over injectable dosage forms.

It is estimated that approximately 200,000 people in Massachusetts are living with $\mathrm{HCV}$ infection. ${ }^{9}$ To promote the use of cost-effective regimens and provide adherence support, the University of Massachusetts Medical School's (UMMS) Clinical Pharmacy Services collaborated with the Massachusetts Medicaid (MassHealth) program to develop a comprehensive HCV medication management program for the fee-for-service (FFS) and primary care clinician (PCC) plans. The program includes dynamic, evidence-based prior authorization (PA) criteria and prescriber outreach to recommend optimized regimens and provide refill reminders. The purpose of this study was to describe the effect of this program on optimized regimen use, PA modifications, and medication cost avoidance in a state Medicaid program.

\section{Methods}

MassHealth provides pharmacy benefits for over 800,000 members in the FFS and PCC plans. The UMMS Clinical Pharmacy Services division is contracted by MassHealth to provide formulary support and manage PA requests. The UMass Investigational Review Board (IRB) reviewed the quality improvement study protocol and determined that this activity was not human subject research. As such, review and approval by the IRB was not required for this analysis.

\section{Program Development}

This comprehensive program consisted of a 2-tiered prescriber outreach: (1) regimen outreach to promote optimized regimen selection and (2) refill outreach to support medication adherence. A medication review was conducted to determine an appropriate PA management strategy for the breakthrough HCV medications. This process included consideration of value to the payer and review of recommendations with key stakeholders (e.g., Massachusetts Medicaid policymakers and physician representatives). PA criteria were developed to identify regimens optimized for efficacy, safety, and cost. An optimized regimen is defined as one that (a) fulfills clinical criteria for genotype, disease staging, prior treatment history, and other member-specific factors; (b) provides similar or improved cure rates compared with the originally requested regimen; and (c) represents the most cost-effective option. The most recent AASLD/IDSA guidelines and current literature were used as the backbone for clinical recommendations, and the PA criteria are updated frequently to reflect guideline and FDA labeling changes.

PA review was conducted by a team of pharmacists trained in the management of $\mathrm{HCV}$ infection. Documentation of demographic information including HCV genotype, previous treatment history, and liver fibrosis staging was required, since these factors are pertinent to regimen selection. Management of drug-drug interactions and clinical rationale for the requested regimen were also considered during the review process. Using information obtained from the PA request, prescriber outreach was conducted in each case where the originally requested regimen was not considered optimized per PA criteria, and an intervention was made to switch to this optimized regimen.

Prescriber outreach to support medication adherence was implemented on March 10, 2014. To identify members who were nearly or past due for a refill, an automated report was generated 3 times weekly. This report identified members who did not have a subsequent paid claim for sofosbuvir or simeprevir within 25 days of the previous claim. Prescriber outreach was performed before the due date of the medication refill to prevent potential gaps in therapy. Members were excluded from outreach if there was a paid claim for the HCV medication since the report was generated, documentation of late treatment start, or change in insurance coverage. Ledipasvir/sofosbuvir was added to the report on October 13, 2014.

A pharmacy technician performed prescriber outreach to request that the prescriber's representative contact the member and/or pharmacy to facilitate a refill, if needed. If deferral or discontinuation of treatment was confirmed, the PA was closed after correspondence with the prescriber. If it was confirmed that treatment initiation had been postponed, the PA duration was extended. The goal of this proactive approach was to support adherence by maintaining active PAs throughout an amended treatment course and simultaneously prevent unnecessary cost by avoiding inadvertent pharmacy claims for members not actively receiving treatment. In addition, this process was designed to ensure that future treatment decisions were re-evaluated through a subsequent PA process.

\section{Program Outcomes}

Regimen Outreach. Members with an approved PA for simeprevir, sofosbuvir, or ledipasvir/sofosbuvir between December 18, 2013, and January 31, 2015, were included in the analysis. The program received the first PA for a breakthrough HCV medication on December 18, 2013. Successful regimen outreach was defined as the number of members for whom an optimized regimen recommendation was accepted by the prescriber. Optimized regimen recommendations included 1 or more changes to the regimen, including extended duration 
of therapy, shortened duration of therapy, and/or change to the medications in the regimen.

Refill Outreach. Refill outreach was assessed for all members with an approved PA between March 10, 2014, and January 31, 2015. The outcome measure for refill outreach was the number of PA modifications (closure or extension) made as a result of outreach.

Medication Cost Avoidance and Return on Investment. Medication cost avoidance, from the perspective of MassHealth, was calculated for members who completed treatment with an optimized regimen, as inferred by pharmacy claims data. It was calculated as the difference in cost between the HCV regimen originally requested by the prescriber and the optimized $\mathrm{HCV}$ regimen recommended by the pharmacist. Members were presumed to have completed treatment if the total days supply for approved HCV medications based on claims data matched the approved treatment duration. Based on our definition of an optimized regimen, cure rates resulting from treatment with the originally requested and optimized regimens were assumed to be equal. We used wholesale acquisition cost to calculate medication costs. ${ }^{10}$

Return on investment (ROI) was based on a cost-avoidance model that balanced the start-up and maintenance costs of the program with cost avoidance realized from regimen switches. Resources for the program start-up consisted of pharmacist, data analysis, and management time for clinical research; PA criteria development; presentations; and meetings. Program maintenance costs consisted of time for PA review, outreach phone calls, data tracking, reporting, presentations, and meetings, as well as managerial oversight.

\section{Results}

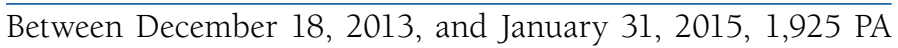
requests for simeprevir, sofosbuvir, or ledipasvir/sofosbuvir were submitted for 1,084 unique members. Requests for 911 unique members (84.0\%) were approved and included in the analysis. PA requests for the remaining 173 members were not approved during this time frame because of lack of information that would have guided the selection of an optimized regimen.

\section{Regimen Outreach}

Of the 911 members with approved PAs, the originally requested regimen for 688 (75.5\%) members was for an optimized regimen. The remaining 223 members (24.5\%) met the criteria for prescriber outreach to recommend switching to an optimized regimen. Pharmacist interventions to change to an optimized regimen were accepted for 135 members (60.5\%). The most common regimen change was shortened duration of therapy (55 of 135 regimen changes). The only reason provided to decline an optimized regimen was documented clinical rationale to avoid a peginterferon alfa-containing

\begin{tabular}{l|c}
\hline \multicolumn{1}{c|}{ TABLE 1 } & $\begin{array}{c}\text { Prior Authorization Interventions } \\
\text { Resulting from Refill Outreach }\end{array}$ \\
\hline PA Intervention & Number of PAs \\
\hline Total PA interventions & 102 \\
\hline PA closed & 69 \\
\hline Treatment deferral & 21 \\
\hline Adverse drug reaction and drug interaction & 17 \\
\hline $\begin{array}{l}\text { Loss to follow-up, nonadherence to medication, } \\
\text { and nonadherence to illicit drug abstinence }\end{array}$ & 20 \\
\hline $\begin{array}{l}\text { Illness/hospitalization, death, loss of coverage, } \\
\text { and change in treatment plan }\end{array}$ & 11 \\
\hline PA extended & 33 \\
\hline Prescriber updated treatment start date & 33 \\
\hline PA = prior authorization. & \\
\hline
\end{tabular}

regimen for members with genotype 3 infection or genotype 2 infection who were treatment-experienced with cirrhosis $(n=88)$. Specific reasons included psychiatric history or prescriber preference to treat with the AASLD/IDSA guidelinepreferred regimen of sofosbuvir plus ribavirin.

\section{Refill Outreach}

Between March 10, 2014, and January 31, 2015, 715 members were identified for a refill outreach intervention. Of these, 200 did not require outreach because of a same day refill, documentation of a late start, or change in insurance coverage. Prescribers were contacted for 515 members to inform of an upcoming refill for an HCV medication. As a result of the outreach, $19.6 \%$ of members had a subsequent PA modification (101 of 515 members). Sixty-nine approved PAs (for 68 members) were closed after correspondence with the prescriber, and 33 approved PAs (for 33 members) were extended (Table 1). The remaining 414 members completed refills for their HCV regimens. The most common reason for closing a PA was treatment deferral (21/69 PA closures). Pharmacies for 2 of 68 members for whom PAs were closed attempted to submit a claim for a novel HCV agent within 6 days after PA closure, which was rejected at the point of sale. The estimated drug waste cost avoidance by proactively closing these PAs was $\$ 56,000$.

\section{Medication Cost Avoidance and Return on Investment}

Of the 135 members approved for an optimized regimen, 111 $(82.2 \%)$ completed therapy. The projected cost avoidance for these members between December 18, 2013, and January 31, 2015 , was $\$ 3,770,097$ (Table 2). The greatest cost avoidance was derived from shortening ledipasvir/sofosbuvir treatment duration from 12 to 8 weeks for 44 treatment-naïve, noncirrhotic members with genotype 1 infection and baseline HCV viral load below 6 million IU/mL.

Start-up costs for the program were $\$ 36,641$, while the cost to run the program during the study period was $\$ 330,186$. Based on the estimated cost avoidance of $\$ 3,770,097$ and total 


\begin{tabular}{|c|c|c|c|c|c|}
\hline Type of Regimen Change & Genotype & Original Regimen & Optimized Regimen & $\begin{array}{c}\text { Number of } \\
\text { Members }\end{array}$ & $\begin{array}{l}\text { Projected Cost } \\
\text { Avoidance }^{\mathrm{a}}(\$)\end{array}$ \\
\hline \multirow{6}{*}{$\begin{array}{l}\text { Changed medication and/or } \\
\text { extended duration }\end{array}$} & 1 & $\mathrm{SOF}+\mathrm{PEG}+\mathrm{RBV} \times 12 \mathrm{~W}$ & $\mathrm{SOF}+\mathrm{SMV} \times 12 \mathrm{~W}$ & \multirow[t]{6}{*}{17} & \multirow[t]{6}{*}{$-766,487$} \\
\hline & 1 & LDV/SOF $\times 12 \mathrm{~W}$ & $\mathrm{LDV} / \mathrm{SOF}+\mathrm{RBV} \times 12 \mathrm{~W}$ & & \\
\hline & 1 & $\mathrm{SOF}+\mathrm{SMV} \times 12 \mathrm{~W}$ & $\mathrm{LDV} / \mathrm{SOF} \times 24 \mathrm{~W}$ & & \\
\hline & 1 & LDV/SOF $\times 12 \mathrm{~W}$ & $\mathrm{LDV} / \mathrm{SOF} \times 24 \mathrm{~W}$ & & \\
\hline & 1 & $\mathrm{LDV} / \mathrm{SOF} \times 8 \mathrm{~W}$ & $\mathrm{LDV} / \mathrm{SOF} \times 12 \mathrm{~W}$ & & \\
\hline & 3 & $\mathrm{LDV} / \mathrm{SOF} \times 12 \mathrm{~W}$ & $\mathrm{LDV} / \mathrm{SOF}+\mathrm{RBV} \times 12 \mathrm{~W}$ & & \\
\hline \multirow[t]{5}{*}{ Changed medication } & 1 & $\mathrm{SOF}+\mathrm{PEG}+\mathrm{RBV} \times 12 \mathrm{~W}$ & $\mathrm{LDV} / \mathrm{SOF} \times 12 \mathrm{~W}$ & \multirow[t]{5}{*}{15} & \multirow[t]{5}{*}{680,630} \\
\hline & 1 & $\mathrm{SOF}+\mathrm{SMV} \times 12 \mathrm{~W}$ & $\mathrm{SOF}+\mathrm{PEG}+\mathrm{RBV} \times 12 \mathrm{~W}$ & & \\
\hline & 1 & $\mathrm{SOF}+\mathrm{SMV} \times 12 \mathrm{~W}$ & $\mathrm{LDV} / \mathrm{SOF} \times 12 \mathrm{~W}$ & & \\
\hline & 4 & LDV/SOF $\times 12 \mathrm{~W}$ & $\mathrm{PrOD}+\mathrm{RBV} \times 12 \mathrm{~W}$ & & \\
\hline & 4 & $\mathrm{SOF}+\mathrm{SMV} \times 12 \mathrm{~W}$ & LDV/SOF $\times 12 \mathrm{~W}$ & & \\
\hline \multirow[t]{3}{*}{ Shortened duration } & 1 & LDV/SOF $\times 12 \mathrm{~W}$ & $\mathrm{LDV} / \mathrm{SOF} \times 8 \mathrm{~W}$ & \multirow[t]{3}{*}{52} & \multirow[t]{3}{*}{$2,142,000$} \\
\hline & 1 & $\mathrm{LDV} / \mathrm{SOF} \times 24 \mathrm{~W}$ & $\mathrm{LDV} / \mathrm{SOF} \times 12 \mathrm{~W}$ & & \\
\hline & 4 & LDV/SOF $\times 24 \mathrm{~W}$ & LDV/SOF $\times 12 \mathrm{~W}$ & & \\
\hline \multirow{8}{*}{$\begin{array}{l}\text { Shortened duration and } \\
\text { changed medication }\end{array}$} & 1 & $\mathrm{SOF}+\mathrm{RBV} \times 24 \mathrm{~W}$ & $\mathrm{LDV} / \mathrm{SOF} \times 12 \mathrm{~W}$ & \multirow[t]{8}{*}{27} & \multirow[t]{8}{*}{$1,713,954$} \\
\hline & 1 & $\mathrm{SOF}+\mathrm{RBV} \times 24 \mathrm{~W}$ & $\mathrm{SOF}+\mathrm{PEG}+\mathrm{RBV} \times 12 \mathrm{~W}$ & & \\
\hline & 1 & $\mathrm{SOF}+\mathrm{RBV} \times 24 \mathrm{~W}$ & $\mathrm{SOF}+\mathrm{SMV} \times 12 \mathrm{~W}$ & & \\
\hline & 1 & $\mathrm{SOF}+\mathrm{SMV} \times 12 \mathrm{~W}$ & $\mathrm{LDV} / \mathrm{SOF} \times 8 \mathrm{~W}$ & & \\
\hline & 1 & $\mathrm{SOF}+\mathrm{SMV} \times 24 \mathrm{~W}$ & $\mathrm{LDV} / \mathrm{SOF}+\mathrm{RBV} \times 12 \mathrm{~W}$ & & \\
\hline & 1 & $\mathrm{LDV} / \mathrm{SOF} \times 24 \mathrm{~W}$ & $\mathrm{LDV} / \mathrm{SOF}+\mathrm{RBV} \times 12 \mathrm{~W}$ & & \\
\hline & 3 & $\mathrm{SOF}+\mathrm{RBV} \times 24 \mathrm{~W}$ & $\mathrm{LDV} / \mathrm{SOF}+\mathrm{RBV} \times 12 \mathrm{~W}$ & & \\
\hline & 3 & $\mathrm{SOF}+\mathrm{RBV} \times 24 \mathrm{~W}$ & $\mathrm{SOF}+\mathrm{PEG}+\mathrm{RBV} \times 12 \mathrm{~W}$ & & \\
\hline \multicolumn{4}{|l|}{ Total } & 111 & $3,770,097$ \\
\hline
\end{tabular}

${ }^{a}$ Cost avoidance is calculated as the difference between the cost of the initially requested regimen and the cost of the recommended and approved regimen. Medication prices have not been adjusted to reflect the federal rebate.

LDV/SOF=ledipasvir/sofosbuvir; $\operatorname{PrOD}=$ paritaprevir/ritonavir/ombitasvir/dasabuvir; $P E G=$ peginterferon alfa; $R B V=$ ribavirin; $S M V=$ simeprevir; $S O F=$ sofosbuvir;

$W=$ weeks.

program cost of $\$ 366,827$, the program demonstrated an $\mathrm{ROI}$ of $\$ 10.28$ for every $\$ 1$ spent.

\section{Discussion}

Direct-acting antiviral medications represent a true breakthrough in the treatment of chronic HCV infection. In this study, we report one state's Medicaid experience with a comprehensive HCV medication management program. Nearly $25 \%$ of the members with an approved PA for a novel HCV medication were eligible for an optimized regimen recommendation based on program criteria. Of these members, 60.5\% had regimens changed by the prescriber upon intervention by a pharmacist. This comprehensive approach has allowed the Massachusetts Medicaid program to provide access to curative $\mathrm{HCV}$ regimens with a projected cost avoidance of over $\$ 3.7$ million in medication spend in just under 14 months.

The most commonly recommended regimen change was shortening ledipasvir/sofosbuvir treatment duration from 12 to 8 weeks for treatment-naive, noncirrhotic members with $\mathrm{HCV}$ viral load below 6 million $\mathrm{IU} / \mathrm{mL}$. This recommendation is supported by the FDA's post hoc analysis of the ION-3 study, which found comparable response rates between the 8-week and 12-week treatment with ledipasvir/sofosbuvir (97\% vs. 96\%) in this patient population. ${ }^{11,12}$

Prescribers for 88 members with genotype 2 or 3 infection provided a clinical rationale for not treating with a peginterferon alfa-containing regimen. Sofosbuvir plus peginterferon alfa and ribavirin was an alternative regimen recommended by the AASLD/IDSA guidelines for all interferon-eligible patients with genotype 3 infection and some patients with genotype 2 infection, based on high response rates and short duration of therapy. While the recommendation is supported by the results of several studies that found high sustained virologic response (SVR) rates (83\%-97\%) in patients with genotype 2 and 3 infection, ${ }^{13-15}$ recognizing potential challenges with peginterferon alfa tolerability, prescribers were allowed to bypass this regimen if specific clinical rationale was provided. The AASLD/ IDSA guidelines and clinical criteria have since been updated to reflect recent data suggesting superiority of peginterferon alfa-containing regimens, as well as sofosbuvir plus daclatasvir regimens over sofosbuvir plus ribavirin regimens in the treatment of HCV genotype 3., ${ }^{5,16}$ 
Clinical literature shows that increased adherence to HCV therapy is associated with improved likelihood of achieving SVR. ${ }^{17}$ Clinic visits or telephone contact are recommended during treatment to ensure medication adherence and to monitor for adverse events and potential drug-drug interactions with newly prescribed medications. ${ }^{5}$ Our program included prescriber outreach to provide refill reminders as a method to support adherence and avoid unnecessary cost. Refill outreach identified that $19.6 \%$ of members required PA intervention because of changes in the treatment plan. These modifications minimize the potential for inadvertent fills by pharmacies or interruption in therapy because of a late treatment start. We believe our claims-driven refill outreach provides an opportunity for a communication link between members and prescribers who may be unaware of issues with medication compliance.

The AASLD/IDSA guideline recommends pretreatment assessment of a patient's understanding of treatment goals and provision of education on the importance of adherence and follow-up care. ${ }^{5}$ This approach may optimize treatment outcomes by tailoring the management strategies to patientspecific needs. Our analysis showed that the majority of members who required PA extension started treatment late because of the scheduling of a teaching appointment or patient lack of readiness ( 25 of 33 members). Through flexibility in PA extension, we may be improving the capacity of prescribers to frame effective disease management strategies for HCV infection.

This program was quickly able to pay for itself based on the cost avoidance generated from switching members to optimized regimens. It is important to note that cure rates were not incorporated into the cost-avoidance projections. A more nuanced approach would have been to adjust the cost avoidance based on expected or observed cure rates. Nevertheless, the PA criteria was constructed to recommend an optimized regimen only if the anticipated cure rate based on clinical trial data was similar or higher than that with the originally requested regimen.

\section{Limitations}

This analysis is subject to several limitations. First, although the analysis demonstrated the value of monitoring refills to $\mathrm{HCV}$ regimens in terms of PA modifications, data did not provide information regarding member adherence. Second, although the analysis demonstrated cost avoidance from switching members to an optimized regimen, we did not report virologic cure rates. Therefore, members who did not achieve cure may require retreatment, incurring additional cost to the health plan. For members who did not achieve cure, it is unclear whether use of the originally requested regimen would have led to a better therapeutic outcome. Third, we associated drug waste-related cost avoidance with attempts to adjudicate claims for 2 members for whom treatment had previously been discontinued. It is possible that the pharmacies would have verified that the members were still receiving treatment with the members and/or prescribers before dispensing. Finally, the projected cost-avoidance figures would have been lower had they been adjusted to account for federal drug rebates.

\section{Conclusions}

In light of escalating drug costs, comprehensive HCV medication management administered in a state Medicaid program can help contain costs while ensuring that members have access to clinically optimized regimens. When designing a medication management program, it is important to be dynamic and up to date and to address adherence.

\section{Authors}

PAVEL LAVITAS, PharmD, BCPS; MARK TESELL, PharmD, BCPS; TASMINA HYDERY, PharmD, MBA, CGP; BONNIE C. GREENWOOD, PharmD, BCPS; and MYLISSA PRICE, RPh, MPH, Clinical Pharmacy Services, University of Massachusetts Medical School, Shrewsbury, Massachusetts. KIMBERLY LENZ, PharmD, and PAUL JEFFREY, PharmD, Office of Clinical Affairs, University of Massachusetts Medical School, Quincy, Massachusetts.

AUTHOR CORRESPONDENCE: Bonnie C. Greenwood, PharmD, BCPS, Clinical Program Director, Clinical Pharmacy Services, University of Massachusetts Medical School, 333 South St., Shrewsbury, MA 01545. Tel.: 774.455.3198;

E-mail: Bonnie.Greenwood@umassmed.edu.

\section{DISCLOSURES}

No outside funding supported this study. Lavitas reports personal fees and nonfinancial support from University of Tennessee, Advanced Studies in Medicine and grant funding from Bristol-Myers Squibb, outside the submitted work. All other authors report no conflicts of interest.

The poster "Overview of a Hepatitis C Medication Monitoring Program in a State Medicaid Program" was presented October 8, 2014, by Lavitas at the AMCP Nexus 2014 meeting in Boston, Massachusetts. A program update was presented at the 2015 American Drug Utilization Review Society Meeting on February 27, 2015.

Study concept and design were contributed by Price, Lenz, and Jeffrey, with assistance from Lavitas, Tesell, and Hydery. Lavitas, Tesell, and Hydery collected the data, assisted by Price, Lenz, and Jeffrey, and data interpretation was performed by all authors. The manuscript was written by Greenwood, Lavitas, Tesell, and Hydery, with assistance from the other authors, and was revised by all authors.

\section{ACKNOWLEDGMENTS}

The authors thank the staff of University Massachusetts Medical School Clinical Pharmacy Services for their participation in the comprehensive HCV medication management program and for gathering the data used in this report. 


\section{REFERENCES}

1. Denniston MM, Jiles RB, Drobeniuc J, et al. Chronic hepatitis $C$ virus infection in the United States, National Health and Nutrition Examination Survey 2003 to 2010. Ann Intern Med. 2014;160(5):293-300. Available at: https://www.ncbi.nlm.nih.gov/pmc/articles/PMC4562398/. Accessed September 3, 2016

2. Centers for Disease Control and Prevention. Viral hepatitis - statistics \& surveillance. May 31, 2015. Available at: http://www.cdc.gov/hepatitis/statistics/. Accessed September 3, 2016.

3. Holmberg SD, Spradling PR, Moorman AC, Denniston MM. Hepatitis C in the United States. N Engl J Med. 2013;368(20):1859-61.

4. Yehia BR, Schranz AJ, Umscheid CA, Lo Re V 3rd. The treatment cascade for chronic hepatitis $C$ virus infection in the United States: a systematic review and meta-analysis. PLoS One. 2014;9(7):e101554. Available at: http:// www.plosone.org/article/fetchObject.action?uri=info:doi/10.1371/journal. pone.0101554\&representation=PDF. Accessed September 3, 2016.

5. AASLD-IDSA. Recommendations for testing, managing, and treating hepatitis C. July 15, 2015. Available at: http://www.hcvguidelines.org. Accessed September 3, 2016.

6. Chhatwal J, Kanwal F, Roberts MS, Dunn MA. Cost-effectiveness and budget impact of hepatitis $C$ virus treatment with sofosbuvir and ledipasvir in the United States. Ann Intern Med. 2015;162(6):397-406. Available at: https://www.ncbi.nlm.nih.gov/pmc/articles/PMC4435698/. Accessed September 3, 2016.

7. Mohammad RA, Bulloch MN, Chan J, et al. Provision of clinical pharmacist services for individuals with chronic hepatitis $C$ viral infection: joint opinion of the GI/liver/nutrition and infectious diseases practice and research networks of the American College of Clinical Pharmacy. Pharmacotherapy. 2014;34(12):1341-54.

8. Vo KP, Vutien P, Akiyama MJ, et al. Poor sustained virological response in a multicenter real-life cohort of chronic hepatitis $C$ patients treated with pegylated interferon and ribavirin plus telaprevir or boceprevir. Dig Dis Sci. 2015;60(4):1045-51.

9. Massachusetts Department of Public Health. Clinical advisory: routine screening for hepatitis C. October 2014. Available at: http://www.mass.gov/ eohhs/docs/dph/aids/hcv-clinical-advisory.pdf. Accessed September 3, 2016.
10. Truven Health Analytics. Red Book Online [database]. Updated periodically. September 29, 2015. Greenwood Village, CO.

11. Kowdley KV, Gordon SC, Reddy R, et al. Ledipasvir and sofosbuvir for 8 or 12 weeks for chronic HCV without cirrhosis. N Engl J Med. 2014;370(20):1879-88. Available at: http://www.nejm.org/doi/pdf/10.1056/ NEJMoal402355. Accessed September 3, 2016.

12. HARVONI (ledipasvir and sofosbuvir) tablets, for oral use. Gilead. Revised June 2016. Available at: https://www.gilead.com/ /media/Files/pdfs/medicines/liver-disease/harvoni/harvoni_pi.pdf. Accessed September 3, 2016.

13. Lawitz E, Poordad F, Brainard DM, et al. Sofosbuvir in combination with peginterferon-ribavirin for 12 weeks in previously treated patients with hepatitis C genotype 2 or 3 and cirrhosis. Hepatology. 2015;61(3):769-75. Available at: http://www.ncbi.nlm.nih.gov/pmc/articles/PMC4365682/. Accessed September 3, 2016

14. Lawitz E, Lalezari JP, Hassanein T, et al. Sofosbuvir in combination with peginterferon alfa-2a and ribavirin for non-cirrhotic, treatment-naive patients with genotypes 1, 2, and 3 hepatitis $C$ infection: a randomised, double-blind, phase 2 trial. Lancet Infect Dis. 2013;13(5):401-8. Available at: http://www.sciencedirect.com/science/article/pii/S1473309913700331 Accessed September 3, 2016

15. Gane EJ, Stedman CA, Hyland RH, et al. Nucleotide polymerase inhibitor sofosbuvir plus ribavirin for hepatitis C. N Engl J Med. 2013;368(1):34-44. Available at: http://www.nejm.org/doi/pdf/10.1056/NEJMoal208953. Accessed September 3, 2016.

16. Foster GR, Pianko S, Brown A, et al. Efficacy of sofosbuvir plus ribavirin with or without peginterferon-alfa in patients with hepatitis $C$ virus genotype 3 infection and treatment-experienced patients with cirrhosis and hepatitis C virus genotype 2 infection. Gastroenterology. 2015;149(6):1462-70. Available at: http://www.sciencedirect.com/science/article/pii/S001650 8515010690. Accessed September 3, 2016.

17. Agency for Healthcare Research and Quality. Executive summary. Interventions to improve patient adherence to hepatitis $C$ treatment: comparative effectiveness. Comparative Effectiveness Review No. 91. December 2012. Available at: http://effectivehealthcare.ahrq.gov/ehc/ products/326/1364/CER91_HepCTreatmentAdherence_executivesummary_20121213.pdf. Accessed September 3, 2016. 